\title{
aniki
}

Revista Portuguesa da Imagem em Movimento Portuguese Journal of the Moving Image

\section{Aspectos da dramaturgia num projeto de video mapping de dança: o caso do projeto 'Espaço Tempo Movimento' (ETM)}

Lenine Vasconcellos de Oliveira ${ }^{1}$

\section{Introdução}

O projeto ‘Espaço Tempo Movimento' (ETM) surgiu de uma parceria entre artistas, empresas e instituições, e teve como objetivo principal a realização de um video mapping de dança na fachada principal do prédio do Centro Coreográfico do Rio de Janeiro (CCO). O objetivo era promover de maneira amplamente acessível ao público, esse espaço cultural dedicado à dança através de um notório formato artístico interdisciplinar, no qual a dança estivesse envolvida de maneira protagonista. Estiveram envolvidos: a Secretaria de Cultura do Município do Rio de Janeiro, a Midena Works Estúdio de Arte e Tecnologia, a Cia Híbrida de dança, a Universidade Federal do Rio de Janeiro (UFRJ), o CCO e a produtora Burburinho Cultural. A minha participação se deu mais intensamente como dramaturgo da proposta. O presente artigo procura apontar que possibilidades estão acessíveis à dramaturgia nesse formato tão particular de projeção. No mesmo sentido, de maneira mais pontual, pode-se perguntar: com quais elementos a construção dramatúrgica está convidada a dialogar nessa modalidade artística? Este relato pretende fornecer pistas que auxiliem no estudo do video mapping. Mais especificamente, no apontamento de elementos que nortearam as escolhas dramatúrgicas feitas quando da elaboração do referido projeto, em uma perspectiva que pode-se entender como "por dentro", uma vez que o autor deste artigo foi também partícipe da equipe.

A premissa básica, inicial, de confecção do projeto foi ter na Física, mais especificamente em temas da Física Moderna - a saber: relatividade restrita e mecânica quântica - a motivação para tratar a temática do afeto na contemporaneidade, exibido no formato de imagem de corpos dançantes. Desta motivação inicial originou o título "Espaço Tempo Movimento", que conduziu, em larga medida, a elaboração coreográfica presente nas cenas, quando do início dos trabalhos.

Porém, o próprio formato escolhido para o projeto, acabou trazendo interferências na dramaturgia, através de questões que se mostraram críticas das escolhas poéticas feitas. Sobre tais questões este texto busca se debruçar, com o objetivo de analisar de dentro de

${ }^{1}$ Escola de Educação Física e Desportos, Universidade Federal do Rio de Janeiro, Av. Carlos Chagas Filho, 540, Cidade Universitária - Ilha do Fundão, CEP 21.941590 Rio de Janeiro. 
sua elaboração algumas particularidades desse formato de cena que influi diretamente na sua lógica e poética de construção, ao tratar de um espetáculo que teve na monumentalidade do suporte e na transitoriedade do público alguns de seus elementos balizadores mais marcantes. Para a reflexão acerca dos aspectos analisados, em um cruzamento entre as balizas (entendidas por nós como objetivas) acima mencionadas e os conceitos filosóficos de 'beleza', 'imagem tautológica' e 'presença' - da maneira que foram tratados, respectivamente, por Roger Scruton, Georges Didi-Huberman e Hans Ulrich Gumbrecht - busca-se explicitar algumas justificativas para as escolhas dramatúrgicas realizadas. Este cruzamento pretende oferecer ao leitor um caminho possível de análise, dando assim um pouco mais de concretude para a compreensão do ofício de dramaturgo dentro de um projeto com tamanha particularidade em relação ao tema. Junta-se a essa abordagem conceitual/prática algumas contribuições de pesquisadores do tema.

A imagem projetada instiga tanto por seu aspecto técnico, como nas possibilidades de desdobramento analítico filosófico que o assunto suscita. A prática do video mapping parece um convite ao diálogo necessário entre as duas abordagens. Dentre modalidades facultadas ao uso poético da técnica (2D, 3D, indoors e outdoors), há um grande potencial exploratório em várias das possibilidades narrativas que o video mapping atende, indo de usos publicitários a fins artísticos mais conceituais (Garcia 2014). Não seria exagero entender essa modalidade de projeção como um caso particular, quase a parte, na história da imagem. Possibilitado atualmente a ocupar uma escala monumental tanto pelo estágio de desenvolvimento e acesso aos projetores necessários para trabalhos dessa ordem, como pelo desenvolvimento computacional que torna acessível o diálogo satisfatório, do ponto de vista estritamente técnico, entre a imagem e praticamente qualquer superfície, o video mapping parece convidar o exercício da dramaturgia a uma conciliação entre mundos aparentemente independentes: o cinema em escala industrial e a prática artística mais artesanal, descompromissada a priori com as pressões naturais àquela lógica de produção, sobretudo com relação ao seu "imediatismo e acessibilidade" (Kemp 2011). Essa conciliação se dá apontada principalmente pela escala monumental facultada à técnica contemporânea do video mapping, praticada no projeto ETM, que trouxe questões, aqui expostas e analisadas, para a elaboração do roteiro.

Talvez o que caracterize de maneira mais determinante o video mapping como modalidade de "vídeo arte" seja o fato de que, nesse caso, abdica-se da neutralidade do suporte para projetar. Ao contrário do cinema, onde se cria um mundo sobre uma tela neutra, o video mapping lança-se a outro desafio, na praticamente obrigatoriedade de estabelecer um diálogo com a superfície de projeção. Do ponto de vista dramatúrgico, dentro de toda a complexidade que a técnica carrega, essa característica é o principal elemento que nos interessa.

Este artigo apresentará o projeto, com os agentes envolvidos em sua elaboração. Em seguida discutirá a partir da monumentalidade 
do suporte e da transitoriedade do público - tomados como elementos definidores na dramaturgia - como os conceitos de 'beleza', 'imagem tautológica' e 'presença' influíram na elaboração do roteiro. Em sequência, dando continuidade ao cruzamento entre os aspectos objetivos e a abordagem filosófica, a análise segue trazendo sua exemplificação nas cenas de forma sequenciada, observando os recursos utilizados e o resultado esperado para cada momento do video mapping. Dessa forma, pretende-se abrir ao leitor o processo de elaboração desse projeto em particular, propiciando a extrapolação de algumas possibilidades de diálogo entre a imagem e a construção buscadas nesse formato.

\section{O projeto ETM}

O projeto ETM surgiu a partir da proposta e iniciativa do cineasta e diretor da Cia Gelmini de videodança, Gustavo Gelmini, contemplada pelo edital "Fomento à Cultura - Viva a Arte!" patrocinado pela Secretaria de Cultura do Município do Rio de Janeiro ${ }^{2}$. A ideia desafiadora era realizar um filme de dança na fachada principal do CCO. Seria um curta-metragem, com cerca de 15 minutos de duração, exibido para os transeuntes da localidade em um horário de grande movimento. O cronograma de execução previa a realização do projeto em um prazo de 4 meses, bastante apertado para a complexidade envolvida. Em outubro de 2015, assim que tivemos o resultado positivo do edital, mergulhamos Gustavo e eu em encontros de discussão acerca do projeto e introdutórios aos temas da relatividade restrita e da mecânica quântica.

Foram alguns meses de conversas, planejamento, discussão, aprendizado e, sempre que possível, de contemplação para a fachada do prédio de 25 metros de altura por 14 metros de largura que seria a nossa "tela". Algumas semanas depois, juntaram-se às conversas o coreógrafo Renato Cruz, a produtora Priscila Seixas e o responsável pelos efeitos de vídeo, Daniel Figueiredo. As reuniões de trabalho aconteciam às terças e os ensaios dos bailarinos às quintas em uma sala de ensaio no próprio CCO e aos sábados na Escola de Educação Física e Desportos da UFRJ. Os encontros de discussão alimentavam o coreógrafo e os ensaios. Indiretamente, uma vez que optamos por não participar a eles as nossas "conversas quânticas relativísticas", alimentaram também os bailarinos. Em breve explicarei o porquê dessa escolha.

Trabalhamos com 4 bailarinos da Cia Híbrida: Daniel Oliveira (Kiriku), Duly Omega, Kapu Araujo e Luciana Monnerat. Escolhemos os bailarinos a partir de vídeos e espetáculos da Cia, baseados na riqueza e na qualidade de movimentação apresentada por cada um deles em montagens anteriores. A criação dos movimentos ficou a cargo do coreógrafo e somente em alguns momentos muito pontuais do processo comparecemos, o diretor e o dramaturgo, aos ensaios. Nossa presença se deu sempre no sentido de acompanhar os materiais

\footnotetext{
${ }^{2}$ Resultado publicado no Diário Oficial do Município do Rio de Janeiro (2015. 69).
} 
criados e, eventualmente, sugerir alguma direção para a criação de movimentos, como a utilização de alguns laboratórios, por exemplo. Renato foi o principal responsável pela comunicação com os bailarinos. Foi criada a coreografia, em formato de cenas encadeadas que, desde o início, o coreógrafo tinha plena ciência de que seriam editadas e fragmentadas em várias outras sequências separadas.

Com a finalização das cenas de movimentos, partimos para a elaboração do roteiro de gravação, planejando o encadeamento do registro das sequências com o intuito de maximizar o aproveitamento do tempo no estúdio de filmagem. Assim, a lógica do registro começou a interferir no ordenamento das sequências criadas. Como a gravação exigia, por vezes, a repetição das tomadas e a Cia Híbrida trabalha com movimentações bastante extremas oriundas da dança de rua, hip-hop e acrobacias, consideramos prudente realizar uma análise prévia dos movimentos para realizar o roteiro de gravação em estúdio. Fizemos esta análise tanto in loco nos últimos ensaios como, posteriormente, analisando o registro em vídeo das atividades, a fim de realizar um cuidadoso planejamento da gravação com o objetivo de evitar a fadiga excessiva dos bailarinos. Participou do set de filmagem também o responsável pelos efeitos de vídeo utilizados. A sua participação, junto com toda a equipe, foi muito importante no sentido de aproveitar ao máximo as possibilidades visuais na pós-produção do material registrado em estúdio.

Os efeitos de vídeo foram concebidos dentro do conceito partilhado pelo diretor e por mim, com a função de valorizar a movimentação dos bailarinos e não de criar um tipo de alegoria que, de alguma maneira, competisse com a dança. Algo que parece uma tentação quando se trata de video mapping em trabalhos recentes, é o fato de os efeitos visuais apresentarem, em algum momento, protagonismo na projeção; o que pode ser verificável em trabalhos realizados nos últimos 10 anos (Anadol 2011; Void 2016; Nuformer 2009; InSynchLab 2012). Porém, a proposta era realizar um video mapping de dança. Assim, para manter a coerência com a nossa proposta, entendemos que a projeção deveria ter e assumir como elemento protagonista essencialmente os bailarinos e sua movimentação. Toda parte de efeitos visuais, dentro da proposta, deveria estar a serviço da Dança. O que se pôde verificar, uma vez que os efeitos mais marcantes observados foram a utilização de silhuetas dos bailarinos e do rastro colorido de suas movimentações na fachada do prédio. Ambos efeitos colaboraram com a transformação da percepção dos movimentos de dança, sem que essa deixasse de protagonizar a imagem projetada.

A conjunção desses elementos, todos indispensáveis, resultou no video mapping ETM. Um trabalho que possui múltiplas formas de acesso ao expectador, dada a sua própria natureza, ao mesmo tempo monumental e transitória. Características que acabaram por delimitar possibilidades de abordagem dramatúrgica que serão tratadas no item seguinte. O desafio adicional de buscar uma livre inspiração na Física Moderna, sobretudo da maneira como encaramos essa proposta, foi também definidor da abordagem dramatúrgica adotada. A pedido do 
coreógrafo, Renato, não foi participado aos bailarinos o conteúdo de Física discutido no início do processo. Dada a complexidade das ideias envolvidas, temeu-se provocar uma certa paralisia, decorrente de uma profunda reflexão que os temas impõem, que poderia atrapalhar o andamento dos ensaios em um cronograma tão limítrofe para a proposta. O pedido do coreógrafo foi prontamente compreendido e aceito pela equipe. As projeções ocorreram, finalmente, nos dias 10, 11,12 e 13 de maio de 2016 , e o teaser pode ser visto na internet ${ }^{3}$ (Cia Gelmini de videodança 2016).

\section{Monumentalidade e transitoriedade no video mapping ETM.}

Já há muito a cena contemporânea teatral impõe uma expansão do entendimento do conceito de dramaturgia. Ou pelo menos exige dos pesquisadores que se debruçam sobre o tema um retorno constante a seu fundamento, buscando algum tipo de justificativa que permita ainda a utilização da "função dramaturgo" em um espetáculo, sem que se perca o sentido e o significado para o termo em relação à sua origem. Sobretudo, quando a cena propõe para este artista um exercício que fuja ao seu entendimento mais imediato e técnico, oriundo do teatro: "conselheiro literal e teatral agregado a uma companhia teatral" (Pavis 2008, 117), se torna ainda mais desafiador designar o que representa essa função. Os entendimentos pósdramático (Lehmann 2007) e de teatro físico (Romano 2008) a respeito da arte teatral já colocaram em questão uma perspectiva de dramaturgia como intrínseca e obrigatoriamente ligada ao texto literal teatral. Consequentemente, abordagens que fujam a uma lógica "textocêntrica" na arte teatral ajudam a abrir a possibilidade para que em um espetáculo de dança se permita a aplicação do conceito de dramaturgia e da função de dramaturgo dentro da equipe, movimento fundamental para se descrever o processo dramatúrgico do projeto ETM. O cinema (outro campo de conhecimento pertinente em trabalhos artísticos de video mapping), por sua vez, utiliza-se de uma lógica de produção já consolidada, que acaba por apaziguar um pouco a inquietação com relação ao ofício do dramaturgo, no sentido em que certa especialização característica à arte e à produção cinematográfica convida a manter as fronteiras entre as funções, pelo menos por ora, ainda claras, ou pelo menos ainda possíveis de serem distinguidas ${ }^{4}$, mesmo que encontremos exemplos de artistas que exibem lógicas de produção alternativas à consolidada indústria cinematográfica (McDonough 2009).

\footnotetext{
${ }^{3}$ Disponível em: https://vimeo.com/169936885 (acesso em 07 de novembro de 2019).

${ }^{4}$ Excetuando-se, obviamente, uma perspectiva pós-cinematográfica e de cinema expandido onde se preserva o caráter artesanal individualizado do fazer artístico, não sendo possível identificar uma lógica comum de produção. Mais detalhes, com inúmeros exemplos, podem ser encontrados nas obras: "Art and the Moving Image: a critical reader" (Tanya Leighton 2008), "Video Art" (Michael Rush 2007), "Audiovisual art + VJ culture" (Michael Falukner/ D-FUSE 2006).
} 
Embora atento ao fato de que o tema "dramaturgia" na cena contemporânea é muito abrangente e de certa forma polêmico, abriremos mão de entrar em outras peculiaridades inerentes à relação entre o conceito de dramaturgia e suas distintas possibilidades de exercício na contemporaneidade, deixando claro que não se pretende esgotar o assunto neste artigo. Em lugar disso, enfatizaremos alguns aspectos pontuais e específicos que influíram diretamente na realização e nas escolhas que nortearam o pensamento dramatúrgico do projeto ETM. Assim, esta seção abordará a influência do suporte, principalmente a sua monumentalidade, e a transitoriedade do público como elementos determinantes para a dramaturgia do video mapping.

A superfície que serviu como tela de projeção do vídeo de dança foi a fachada de um prédio na zona norte da cidade do Rio de Janeiro, Tijuca, bairro de classe média. A construção, que já foi uma fábrica de bebidas, hoje funciona como supermercado e abriga, em alguns andares do prédio do complexo que fica no acesso da rua José Higino, o principal centro cultural público dedicado à dança na cidade do Rio de Janeiro.

Desta forma, o conteúdo do video mapping de dança apresentaria uma imediata conexão com o espaço que abrigaria a sua projeção. Essa foi uma das razões que nos fez optar por uma utilização minimalista dos efeitos visuais dentro da concepção dramatúrgica do projeto. Os movimentos dos bailarinos deveriam assumir o protagonismo por serem movimentos de dança projetados em um centro cultural para a dança, lugar onde essa arte se dá em presença. Apesar da monumentalidade da nossa "tela de projeção", optamos, assim, por direcionar a construção dramatúrgica para que a dimensão da superfície disponível como tela servisse a uma percepção mais rica dos movimentos realizados pelos bailarinos. Ou seja, dentro de nossa proposta dramatúrgica, a temática associada ao local da projeção convidava a utilizar ao máximo os elementos arquitetônicos disponíveis no sentido de fazer com que o prédio não apenas recebesse passivamente, a projeção, mas que sua arquitetura e sua utilização pudessem também "conversar" com o público, através do video mapping ETM. Nesse sentido, todos efeitos visuais utilizados tiveram uma função básica: realçar ou potencializar os movimentos dos bailarinos, sem cair na tentação de abusar dos efeitos visuais. $\mathrm{O}$ video mapping, projetado na fachada de um prédio tão particular, buscou contribuir com o olhar para aquela construção e também para o olhar daquela construção, não em uma lógica arquitetônica imersiva na informação (Colomina 2009; Bruno 2015) mas buscando fazer com que o discurso dramatúrgico convidasse o público a participar do diálogo que ocorre entre a imagem e a construção. Assim, o projeto propiciou ao prédio a possibilidade de "dançar" de uma maneira sutil, sem recorrer a efeitos que envolvessem a simulação de "movimentos" da construção de maneira mais explícita. Entendemos ser mais interessante possibilitar ao prédio "dançar" para o espectador através do realce do trabalho dos bailarinos que produzem arte em seu interior, em muitas das vezes e para muitos de maneira desconhecida 
e silenciosa, graças à pouca notoriedade que a utilização do espaço enquanto centro cultural possui ante o público em geral.

Para descrever e, de certa maneira, estabelecer um diálogo teórico possível para auxiliar na análise de algumas das escolhas que nortearam o pensamento dramatúrgico do projeto ETM, é pertinente recorrer ao filósofo Georges Didi-Huberman (2005), que analisa obras do minimalismo americano, em escultores como Donald Judd e Robert Morris. A abordagem dialógica com que o filósofo analisa o olhar para as obras converge com a justificativa da dramaturgia em momentos do video mapping. ${ }^{5} \mathrm{O}$ nosso desejo, enquanto realizadores do projeto, foi que aquela construção potencializasse a sua significação como espaço de realização de dança. Para fazer isso recorremos ao video mapping como forma de fazer os bailarinos serem transportados para a fachada do prédio, ocupando assim a sua superfície que traça o limite entre o interior e o exterior do prédio, e utilizando detalhes da construção para permitir que a arquitetura "conversasse" com a projeção e com o espectador. Buscou-se uma maneira de, através do video mapping, fazer a dança "transbordar" daquele espaço.

Para possibilitar o diálogo entre, por um lado, a construção, de traços arquitetônicos tão destacados quando confrontados com o seu entorno de prédios residenciais no bairro da Tijuca, e, por outro, os transeuntes, a dramaturgia deveria criar uma possibilidade de interação que permitisse ao prédio "falar" às pessoas, de preferência em uma linguagem pertinente à sua utilização: um centro cultural de e para a dança.

A maneira de conduzir o discurso do prédio, permitindo à construção participar da narrativa exibida, confunde-se com a própria possibilidade fornecida pela técnica de video mapping. Ao ser possível adotar os detalhes arquitetônicos da construção como parte interativa com o conteúdo, abre-se uma porta para que o filme projetado dialogue de maneira muito própria e particular com a superfície receptora. A ideia de tela em branco - tão pertinente às artes pictóricas e também ao cinema em sua versão mais industrial - que se espera de certa maneira passiva, não mais se aplica como plenitude de possibilidades quando a técnica permite (e praticamente exige) expandir o diálogo entre conteúdo projetado e superfície de projeção (Mota 2014). À arquitetura é permitido, e por vezes demandado, assumir o papel de "personagem", contracenando, no caso específico do projeto ETM, com os bailarinos. O diálogo entre o filme e a arquitetura abre espaço para que a construção, dentro de sua monumentalidade fale com os transeuntes desavisados através do filme projetado em sua superfície.

\footnotetext{
${ }^{5}$ Didi-Huberman propõe a possibilidade de que a imagem possa assumir caráter ativo na relação com o observador. Isso se daria através de uma maneira de ver que fuja ao olhar tautológico, segundo a proposição: "Só podemos dizer tautologicamente Vejo o que vejo se recusarmos à imagem o poder de impor a sua visualidade como uma abertura, uma perda (...) é exatamente daí que a imagem se torna capaz de nos olhar" (2005, 105; grifo no original).
} 
Antes de aprofundar a análise da perspectiva dialógica do video mapping ETM, através da exemplificação com as cenas utilizadas e seu confronto principal com a abordagem de Didi-Huberman, é oportuno atentar para outra característica marcante do projeto: a transitoriedade da audiência. Ter no espectador principal não alguém que estaria pré-disposto a assistir algo, mas pessoas em geral em seus mais variados trajetos, foi uma marca do ETM. Desde o início, estávamos cientes da possibilidade de atingir não apenas aqueles que sabiam da ocorrência do video mapping e se dirigiram para o local de exibição. A conjunção de fatores integrantes do ETM abria a possibilidade de capturar a imaginação, ainda que rápida e efemeramente, de pessoas que retornavam de seus locais de trabalho. Mais do que uma possibilidade, esse foi um elemento buscado como objetivo e desafio. Devido ao horário ${ }^{6}$ e ao local da projeção, sabia-se de antemão que a maior quantidade de público com chance de ser atingido seriam os passantes. Há uma parada de ônibus em frente à fachada de projeção. Estávamos diante de um público que, em grande parte, teria o tempo de embarque e desembarque de passageiros do coletivo para contemplar o ETM. Nosso desafio seria conseguir capturar a imaginação dessas pessoas, ainda que assistissem parcialmente à projeção.

Isso acaba impondo uma série de elementos a serem cuidados do ponto de vista dramatúrgico. O roteiro deveria contemplar 3 tipos de público: os que se dirigiram para assistir o video mapping, aqueles que passaram no momento e interromperam as suas trajetórias para assistir ao ETM e os que passavam e viram um trecho da projeção durante seu percurso. Para os dois primeiros, a projeção deveria funcionar dramaturgicamente com uma unidade que permitisse compreender a narrativa como um todo. Para o último, as imagens deveriam oferecer a oportunidade de, mesmo de maneira fragmentada e parcial, permitir a apreciação e fornecer uma ligação com a temática trabalhada: dança inspirada pela física moderna para falar de afeto interpessoal.

Nesse sentido, será de grande valia considerar também o pensamento de Hans Ulrich Gumbrecht sobre a "produção de presença" (2010) que constrói uma poderosa argumentação a respeito dos conceitos de "sentido" e "presença", diferenciando eventos que se referem à produção de sentido em contraponto a outros que produzem presença na percepção do espectador. Em nossa abordagem analítica, é possível também tecer uma relação entre os tipos de eventos, relacionando o pensamento de Gumbrecht com as diferentes condições do espectador no video mapping ETM.

O conceito de "beleza" tal como trabalhado pelo filósofo Roger Scruton também revela-se pertinente em nossa análise, uma vez que evidencia conflitos existentes no ato da apreciação, tanto no

\footnotetext{
${ }^{6} \mathrm{~A}$ ideia inicial era realizar a projeção às $19 \mathrm{~h}$, aproveitando o horário de grande fluxo de pessoas no entorno do prédio. Com a repercussão positiva, a partir do segundo dia, foram realizadas 3 sessões diárias, sendo elas às 18h e 30min, 19h e 19h e $30 \mathrm{~min}$.
} 
reconhecimento do objeto observado, quanto na postura do observador. O roteiro do ETM explorou a possibilidade de existência desses conflitos.

No cruzamento desses elementos - monumentalidade e transitoriedade - entendidos como integrantes e balizadores do projeto, com os conceitos trabalhados por Didi-Huberman, Gumbrecht e Scruton, é possível elaborar certa análise do que foi apresentado, permitindo ao leitor acompanhar o raciocínio norteador das escolhas dramatúrgicas feitas.

\section{Roteiro do video mapping ETM}

Esta análise traz oito momentos do video mapping ETM, que serão chamados neste artigo pela seguinte nomenclatura: Janelas, Solos, Duos I, Rastros, Silhueta I, Duos II, Rostos e Silhueta II. ${ }^{7}$ A proposta de Didi-Huberman, para uma leitura a respeito da visão que fuja à tautologia da imagem é o que guiará a análise dramatúrgica que se segue, como guiou também parte das escolhas feitas quando da elaboração do roteiro. Além das fotos dos dias da projeção, utilizarei como referência em alguns pontos a minutagem do teaser do evento para que o leitor possa ter acesso a algumas imagens, descritas aqui neste artigo em palavras, objetivando dar mais concretude às impressões causadas pelos momentos descritos.

\section{Janelas}

O primeiro momento do video mapping se dá na forma de um convite e tentação ao olhar. Nas três janelas do andar mais alto do prédio, foram projetadas as silhuetas dos bailarinos, permitindo a ilusão de que se observam os movimentos que estariam sendo feitos dentro do prédio, próximo às janelas, como em uma espécie de teatro de sombras. Começa com um bailarino solitário dançando, que logo em seguida ganha a companhia de mais dois, cada qual em sua janela, com as silhuetas aparecendo em sequência (em 0’38” do teaser). O espectador é convidado a assumir uma posição de voyeur. De certo modo, a cena inicial na janela sugere um mergulho no olhar tautológico para o prédio, reforçando seu aspecto de monumentalidade passiva ao mesmo tempo em que exibe de uma maneira muito clara e sutil a sua funcionalidade enquanto centro cultural de dança. O olhar para a dança que acontece por trás da segura fronteira das janelas coloca o espectador na posição confortável de quem observa sem ser observado, podendo contemplar os movimentos, pensados para essa cena pelo coreógrafo Renato, de maneira que funcionassem a partir da percepção de sua silhueta somente.

\footnotetext{
${ }^{7} \mathrm{O}$ roteiro analisado diz respeito à realização do projeto no CCO do Rio de Janeiro em maio de 2016. Desde então o video mapping foi apresentado em outras localidades e construções que, devido a sua diferente arquitetura, exigiram mudanças no roteiro.
} 
Aqui o primeiro efeito visual foi utilizado, assim como aconteceu com os demais, no sentido de valorizar a percepção dos movimentos da dança: a imagem dos bailarinos gravada em estúdio se transformou em silhuetas dançantes projetadas nas janelas. Buscamos a conjunção entre a movimentação e o efeito utilizado, sendo pedido que os bailarinos criassem suas sequências com movimentos que ganhassem destaque e interesse se observados apenas em sua silhueta. Dessa forma, reforçado pelo efeito visual, a primeira imagem do video mapping ilusoriamente não deixa muita dúvida a respeito do que se vê: bailarinos dançando na janela do prédio. Há então um convite imediato ao exercício do que Didi-Huberman chama por "tautologia do olhar" (2005). O ato de ver se destina de maneira apaziguada a um estado contemplativo que aprecia a movimentação dos corpos que acontecem na janela, não restando muita dúvida a respeito da imagem em si, e sobrando espaço para questionamentos a respeito do porquê daqueles corpos dançando ali, nas janelas. Trata-se de corpos sem individualidade ainda, uma vez que não estão plenamente à mostra. Trata-se ainda de silhuetas que podem servir ao nosso olhar a partir de uma perspectiva voyeur, mas que, de maneira ambígua, são de certo modo redimidas pela movimentação apresentada na forma de dança. Não são apenas corpos observados da segurança do anonimato. Sua movimentação coloca o espectador em uma ambiguidade entre a observação (descompromissada e desejosa) e a contemplação. Roger Scruton coloca bem essa distinção, na medida em que aponta certa operação de resgate imposta pelos movimentos de dança àqueles corpos que poderiam ser apenas um objeto de desejo, mas, pela qualidade da movimentação exibida, tornam-se "fins em si mesmos" (2013, 55).

Aquelas silhuetas exibem uma contradição. A sua dança velada é o fim em si mesmo, porém, ainda sem individualidade por não relevar plenamente a imagem do bailarino. O apetite voyeur parece constrangido pela Dança que se exibe, e ao mesmo tempo reforçado pelo anonimato apresentado nas silhuetas sem rostos. Os gestos feitos para aquela apreciação contradizem a imagem tautológica nas janelas, ao mesmo tempo em que o conforto do espectador que observa à distância convida à tautologia. A certeza a respeito do que é visto fraqueja devido à insistência da imagem que dança sem constrangimento na silhueta de um corpo sem rosto visível.

A dramaturgia do Video Mapping ETM parte de uma abordagem sutil no início, em que o espectador é convidado a observar ainda protegido pelo conforto da aparente certeza a respeito daquilo que observa. Mesmo permitindo certa ambiguidade e alguma surpresa, as imagens de silhuetas de bailarinos dançando para a janela funcionam como um primeiro convite a um diálogo entre projeção, arquitetura do prédio e espectador. Através da exibição dessa contradição, o roteiro busca também capturar o espectador transeunte, que estava em seu trajeto nesse momento da projeção. 
O segundo momento do ETM (em 1' 06") se inicia com uma ruptura. O salto mortal para frente, realizado pela silhueta do bailarino Kapu Araújo em uma das janelas, marca o momento em que o filme extrapola tanto em dimensão como em localização a imagem anterior. Da confortável e domesticada imagem da silhueta dançante de um bailarino na janela do CCO, que inicia o salto mortal, o espectador é confrontado com a conclusão desse movimento por um gigante que rompe com os vidros da janela e com a certeza visível da imagem, até certo ponto apaziguada e confortável restrita a uma silhueta na janela.

A movimentação apresentada é similar à observada anteriormente nas janelas. É possível ao espectador reconhecer alguns dos movimentos nos solos dos bailarinos, um após o outro, porém agora exibidos pela imagem de gigantes em uma dimensão compatível com a monumentalidade do prédio que recebe a projeção. Nesse momento transforma-se também o diálogo da projeção com a arquitetura e monumentalidade do prédio. A individualidade, antes suprimida, é acentuada pela dimensão gigante da imagem compatível com o aspecto monumental da construção, que nessa cena permite a visualização em detalhes de rostos e corpos dos bailarinos. Esse momento do ETM convida o espectador a desfazer a sua certeza a respeito da projeção, sendo de certa forma arrancado do conforto de um olhar voyeur e tautológico durante a imagem anterior $\mathrm{e}$ confrontado com uma nova imagem que não apenas quer ser vista mas parecer ser capaz também de olhar. À luz do que propõe DidiHuberman (2005) para esse tipo de confronto com a imagem, no sentido de que a tautologia somente é possível quando são recusadas possibilidades outras de leitura para a imagem que se nos apresenta.

No video mapping ETM o momento dos solos é justamente a cena que propõe uma ruptura com a possibilidade tautológica do olhar. Tanto para o confronto com a monumentalidade do prédio, como na observação dos corpos dos bailarinos, o espectador é arrancado de sua certeza pela transmutação de um bailarino, confortavelmente localizado na janela, em um gigante cujos movimentos ocupam toda a fachada da construção. Neste momento, a projeção abre espaço para uma condição ativa da imagem e do próprio prédio. Do conforto voyeur de quem espia algo pela janela, ainda que impessoal por se tratar apenas da silhueta, o espectador tem à sua contemplação uma nova imagem capaz de fazer toda a monumentalidade do prédio olhar para ele.

Essa transformação provoca no espectador, principalmente naquele transeunte, a oportunidade de ser capturado pelas imagens, o que pode ser visto como o primeiro evento mais intenso de "presença", segundo Gumbrecht (2010), dentro do video mapping. Mesmo para o público desavisado que apenas passava pelo local no momento da exibição, a imagem dos bailarinos projetada de maneira gigante ocupando boa parte da monumental fachada do prédio impõe, sem exageros, um "evento de presença" de tal sorte intenso que não deixa muito espaço para que se passe imune àquele acontecimento. Dessa maneira as imagens dos bailarinos que antes se restringiam ao conforto apaziguado de uma silhueta na janela, agora gritam como 
gigantes que, um após o outro exibem as suas sequências de dança na totalidade da fachada do CCO.

Os solos são interrompidos pela travessia, em sentido horizontal, dos bailarinos na fachada do prédio, agora em tamanho menor. Como uma segunda apresentação, importante sobretudo para os espectadores que começaram a assistir ao ETM a partir dos solos em tamanho gigante, as travessias revelam a qualidade de movimento característica explorada e exibida por cada bailarinos. Em uma última travessia (em 1m19s), agora no sentido da câmera (e em sentido do público que assiste) os quatro bailarinos se "aproximam" de maneira extrema do espectador, culminando com uma inversão da perspectiva exercitada na primeira cena com as silhuetas nas janelas. A imagem do bailarino Duly Omega olha ostensivamente para o espectador como que indagando quem estaria observando a quem, propondo uma inversão nos referenciais de observador e observado. De uma maneira bastante inequívoca, com esse gesto o video mapping permite uma forma quase literal de fazer com que a construção e sua monumentalidade olhem para o espectador, na maneira como sugere Didi-Huberman na quebra da tautologia do olhar. A insegurança na relação entre observador e observado explicitada nesse momento prepara a próxima cena que, pela primeira vez na projeção, mostra a interação entre dois bailarinos.

\section{Duos I}

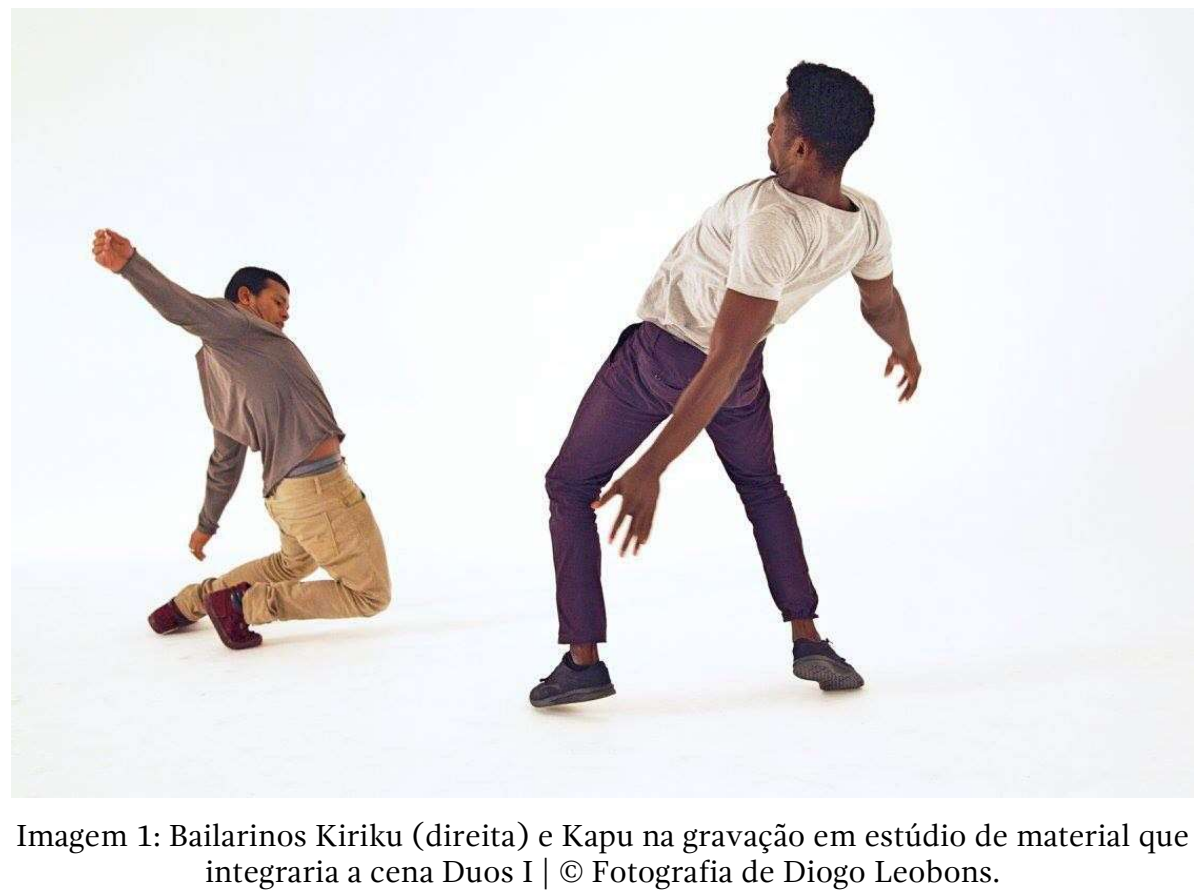

Esse é o primeiro momento no roteiro do video mapping em que é mostrada a interação entre dois bailarinos (em 1m34s), ponto chave da temática do projeto ETM. O tipo de jogo posto à apreciação do expectador mostra na movimentação dos dois bailarinos o efeito corporal de, alternadamente, sofrer e exercer influência sobre o 
outro. Nessa cena, ambos os bailarinos afetam e são afetados. De uma forma nua, a dança que se exibe a partir da afetação mútua procura explicitar as linhas invisíveis que conectam as presenças humanas em cena, e na vida. O risco de experimentar afetar e ser afetado, simplesmente reagindo a uma sutil proposição dada pela intensidade da presença que está a sua frente, faz com que observemos nos corpos dos bailarinos os impulsos - causado e sentido - em função do acontecimento de um encontro despropositado, apenas por ser encontro. Gumbrecht $(2010,127)$ aborda a questão da intensidade na experiência da percepção de um evento de presença, revelando o quão inútil ou pequena pode ser a insistência na busca por uma apreensão racional capaz de transformar em sentido uma presença cuja intensidade não deixa outra opção que não a da simples reação. Ele recorre ao que acontece no seu confronto com a música para exemplificar como, na apreciação de uma ária de Mozart, não se pode antecipar o efeito imprevisível e efêmero causado, seja ele emocional, físico ou cognitivo.

Dentro da poética do ETM, é disso que trata a cena Duos I. Tanto a observação nas reações como a alternância das posições de propositor e receptor no jogo que conduz a movimentação dos bailarinos, revelam a inconstância na experiência do afeto. $\mathrm{O}$ que a dança exibe como ações e reações físicas no formato monumental do ETM pode ser experimentado pelo transeunte que, capturado pelo intenso evento de presença disparado pelas imagens, é atingido por uma interação entre bailarinos que simplesmente reagem e agem de acordo com o que lhes afeta. Esta é uma cena que muito pouco pretende dizer enquanto comunicação racional ao espectador. O objetivo principal é fazer transbordar para quem assiste a reação que cada bailarino experimenta e provoca em função da presença e do encontro com o outro. Assim o video mapping ETM começa a entrar mais explicitamente no tema do afeto interpessoal.

\section{Rastros}

Da primeira cena de encontros o video mapping ETM parte para uma imagem em que a movimentação dos bailarinos deixa seu rastro visível à apreciação. Esta cena (em 1m52s) apresenta os bailarinos realizando solos e se movimentando em grupo. Em ambos os casos, são deixados visíveis rastros coloridos de suas performances. Suas dimensões são intermediárias às dos corpos em silhueta restritos à moldura das janelas e às dos gigantes que ocupam toda a fachada do prédio, exercendo e recebendo afeto na cena imediatamente anterior. O conjunto formado pelos elementos dimensão, movimentação e cor realizam o tingimento da superfície de projeção, transformando a construção, propondo outra forma de interação com a monumentalidade do suporte. 


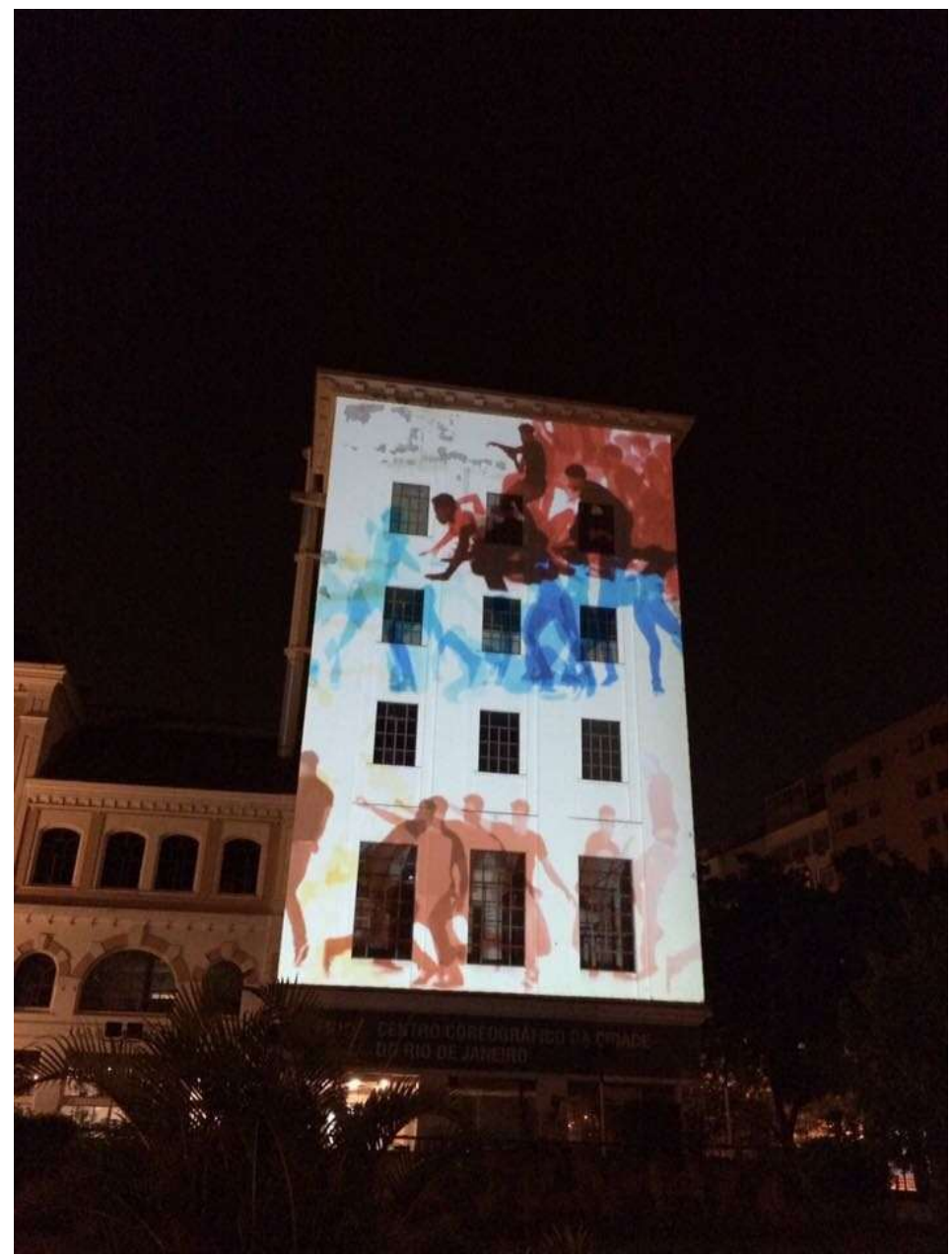

Imagem 2: Percurso realizado pela movimentação dos bailarinos, marcado com efeito visual utilizado na cena Rastros | (c) Fotografia Diogo.

No trajeto percorrido, em diversas direções horizontais e verticais, a fachada de projeção é ocupada por rastros coloridos que possibilitam ao espectador a generosa oportunidade de perceber detalhes da movimentação dos bailarinos. Dessa forma o video mapping permite ao espectador poder ser afetado em uma contemplação que parece esgarçar sua experiência de tempo, uma vez que uma fração do passado realizado no movimento dos bailarinos ganha, com a utilização do efeito gráfico de rastro colorido, outra permanência. O movimento dos bailarinos e a experiência que a sua imagem nos proporciona ganham outra potência de afeto na medida em que a visualização dos rastros deixados nos permite esmiuçar algo que em realidade está aprisionado em uma brecha muito estreita da experiência espaço-temporal. A possibilidade dada pela observação dessa imagem aumenta a medida dessa brecha e convida o olhar a experimentar outro afeto proveniente dos corpos dos bailarinos em movimento, proporcionando outra forma de contemplação para os movimentos.

Nessa cena, algo que é sempre apresentado, na realidade, como efêmero extremo se apresenta com uma existência espalhada no tempo, exposta por um rastro que permite a oportunidade expandida 
de observar detalhes na repetição evanescente projetada. Essa imagem reconfigura o movimento a partir da exibição de outro referencial temporal para a sua exposição.

\section{Silhueta I}

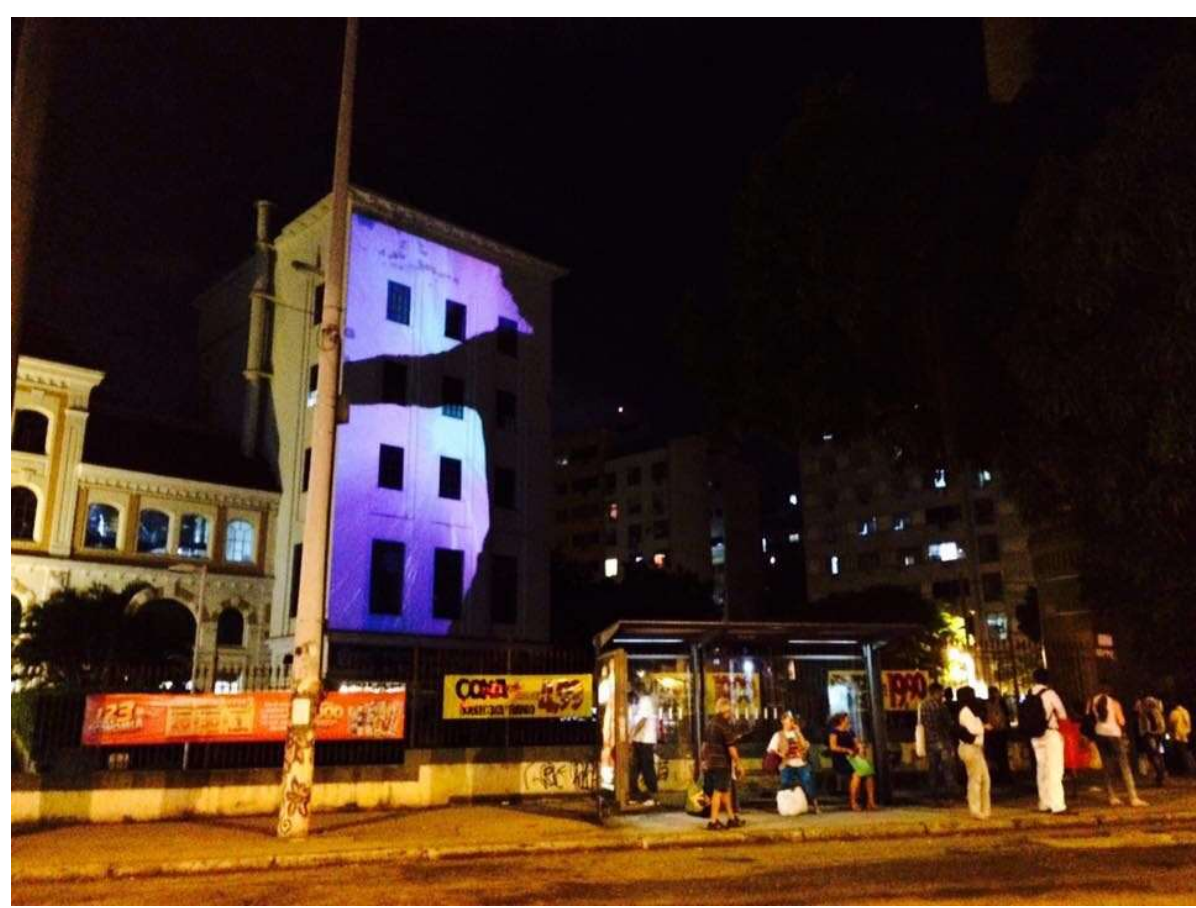

Imagem 3: Silhueta do bailarino Renato Cruz (diretor coreográfico do projeto) na cena Silhueta I | (c) Fotografia de Diogo.

Os rastros são interrompidos por um movimento abrupto. Os bailarinos Luciana Monnerat e Duly Omega, em dimensão gigante cruzam o prédio e, com um gesto de quebra, descortinam na fachada da construção outra realidade (2m32s). O suporte monumental recebe imagens que sugerem uma viagem pelo espaço sideral, servindo de pano de fundo para a sombra gigante de um dos bailarinos, no caso o coreógrafo Renato, que realiza uma movimentação que lhe é extremamente particular.

Novamente o video mapping ETM flerta com certo ilusionismo, na medida em que suscita de novo uma dúvida ao espectador. A exemplo da cena "Janelas", a imagem que vemos possui mais de uma possibilidade de realização. A silhueta que se observa tomando a fachada do prédio tanto poderia ser a projeção de uma imagem filmada, como a sombra do bailarino dançando posicionado na frente do projetor. O espectador que se depara com esse momento do video mapping poderia se ver tentado a buscar pelo bailarino em performance real na frente do projetor. Em contraponto à cena inicial das janelas, que alimentaria certo desejo voyeur no espectador, a possibilidade sugerida pela cena "Silhueta I" representa outra qualidade de risco cênico e de afeto interpessoal. Se a fronteira das janelas delimita um limite seguro entre o bailarino e o olhar, sua 
ausência, nesse caso da silhueta projetada, brinca com a possibilidade do confronto real, do encontro real, arriscado e intenso.

Esse momento do video mapping exibe uma contradição. Embora a silhueta do bailarino sugira que ele possa estar presente, dançando na frente do projetor, o fundo que abriga a sua imagem remete a uma viagem pelo longínquo espaço sideral. A imagem condensa a sensação de longe e perto, distância e proximidade, colocando o risco da experiência do afeto em um lugar de ambiguidade. Aquele bailarino que poderia ter a sua presença real alcançável para o espectador, exibe a sua silhueta sobre um fundo que conduz o olhar para longe, para a infinidade do universo, e sobre esta, a projeção que poderia ser sombra de uma presença tangível e real. A distância que protege é confrontada com a possibilidade de presença produzida pela imagem que nos faz desejar o risco do afeto em um encontro real. Novamente Gumbrecht ajuda a conceituar o que a imagem nessa cena do ETM exibe: "Em outras palavras, falar de 'produção de presença' implica que o efeito de tangibilidade (espacial) surgido com os meios de comunicação está sujeito, no espaço, a movimentos de maior ou menor proximidade e de maior ou menor intensidade" $(2010,38)$. São esses movimentos, condensados em uma única imagem que a cena "Silhuetas I" nos mostra.

\section{Duos II}

Conduzindo para o final (em 3m01s) há um retorno à imagem dos bailarinos em duos. O jogo de afetar e ser afetado, expresso na forma de dança, ganha uma maior intensidade como verborragia de movimentos provocados pela aparente busca por uma resolução. A contemplação dos dois duos alternados - um formado por Duly e Luciana (que flerta com certa ansiedade na qualidade dos movimentos), o outro formado por Kiriku e Kapu (já exibindo ares de exaustão) - neste ponto do video mapping convida à indagação do que buscam aqueles bailarinos. Dessa vez, a pergunta acaba por se impor com mais força, por ser a segunda vez que o jogo aparece dentro da dramaturgia do ETM. Não deixa de passar a impressão de uma falsa fuga, onde um bailarino parece evitar o contato com o outro. Porém, ao mesmo tempo, entre eles percebe-se uma proximidade espacial que não é abandonada. A imagem carrega uma tensão que deseja se resolver. Retomando Gumbrecht, nessa cena os bailarinos corporificam a ambiguidade entre "movimentos de maior ou menor proximidade" $(2010,38)$, ao mesmo tempo oscilando entre o desejo e o temor. Os dois gigantes na fachada do prédio não deixam de exibir certa fragilidade em uma busca por outra qualidade de tangibilidade, diante do número generoso (e quiçá ilusório) de opções de caminhos para o afeto ofertados em abundância pelos meios de comunicação disponíveis. 


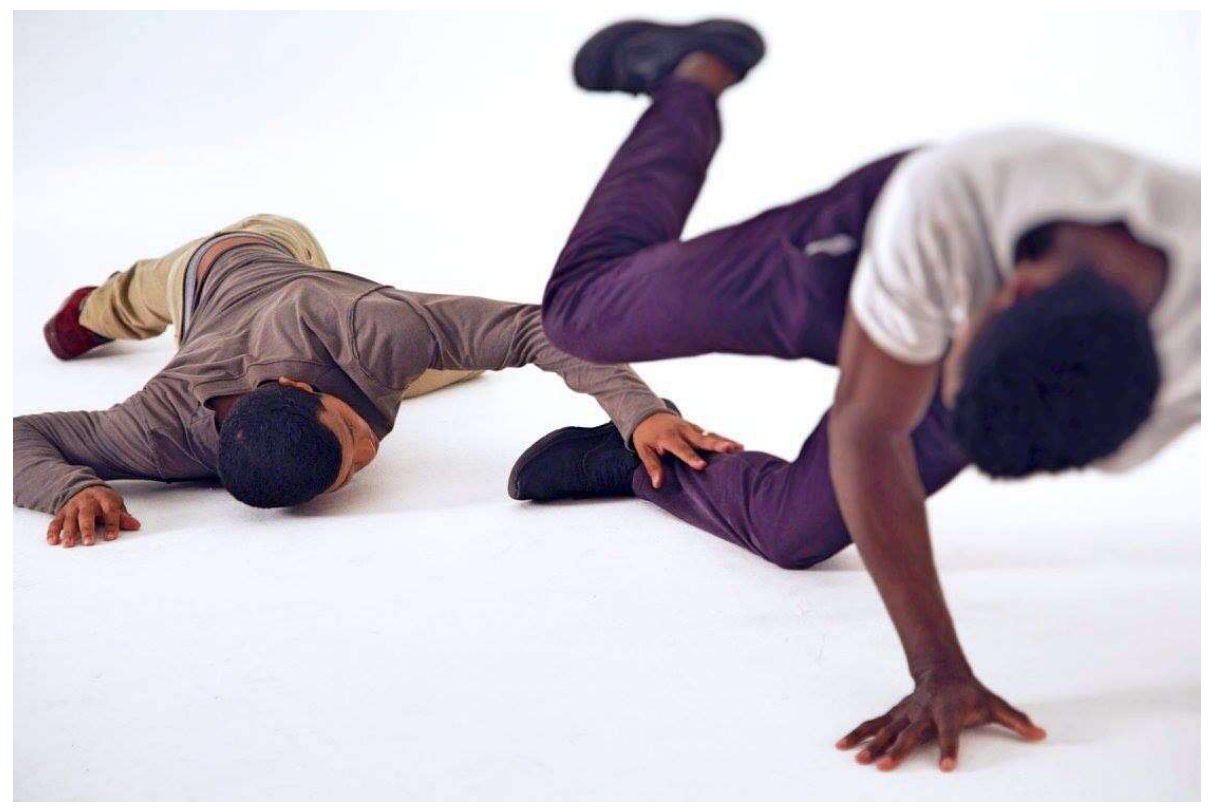

Imagem 4: Bailarinos Kapu (esquerda) e Kiriku em movimentação em estúdio em elaboração do material que será utilizado na cena Duos II | (c) Fotografia de Diogo.

O afeto buscado é de outra natureza. É exibido nos corpos, quando, no momento de resolução, os bailarinos se tocam pela primeira e única vez em todo o video mapping ${ }^{8}$. Esse gesto traz a resolução da tensão que parece contaminar a contemporaneidade, quando cultivamos a tensão da ausência ao viver uma ilusão de contato. Nossos corpos parecem não se convencer da pretensa saciedade afetiva prometida por meios cada vez mais eficazes na personificação distante. Os corpos dos bailarinos, desejoso e temerosos do contato, falam diretamente a esse impulso de querer não ceder à substituição afetiva oferecida por soluções de ausência, intangíveis.

\section{7. e 8. Rostos e Silhueta II}

Como anúncio do fim, é exibido em tamanho grande o rosto dos quatro bailarinos na sequência: Luciana, Duly, Kapu e Kiriku, olhando para o espectador. A última imagem do video mapping ETM (em 3m18s) mostra a silhueta do bailarino Kiriku, realizando a mesma movimentação do início, quando surge como primeiro bailarino dançando nas janelas, mas dessa vez em tamanho grande, ocupando toda a fachada do prédio. Sob o aspecto formal de construção do roteiro, a retomada da primeira imagem exibida auxilia na construção de unidade para o espectador que assistiu a toda a projeção. Para os que assistiram desde o início, a movimentação realizada é de tal sorte marcante e original que auxilia na recondução da memória do espectador. Para a temática tratada, a imensa solidão da imagem monumental do bailarino não deixa de exibir certa fragilidade, encerrando de maneira reflexiva o video mapping.

\footnotetext{
${ }^{8}$ Essa imagem não aparece no teaser.
} 
Agora, de uma maneira menos óbvia e menos explícita, a imagem monumental, assim como o prédio que serve de anteparo, nos olha, segundo a abordagem do filósofo Didi-Huberman. Os movimentos realizados pelo bailarino solitário nos mostram a dimensão de nossa solidão. A mesma imagem que éramos capazes de olhar da condição segura do voyeur que mira um corpo sem subjetividade através de sua sombra na janela, vem ao nosso encontro e nos olha. Mostra-nos um certo caráter insubstituível marcado na busca pelo toque exibido na imagem anterior dos duos. O contraste reflexivo exposto na imagem solitária do bailarino Kiriku ocupando a fachada do prédio e desaparecendo em fade out convida a uma busca pelo que está ausente, pelo afeto ausente.

\section{Considerações finais}

A realização de um video mapping convida a um desafiador exercício de negociação entre vários aspectos inerentes a essa modalidade de arte. No caso do projeto ETM, ao mesmo tempo que as dimensões monumentais oferecem - assim como o cinema - grande acessibilidade ao espectador, a impossível neutralidade da superfície de projeção impõe para a elaboração do roteiro a necessidade de diálogo com a construção que serve de "tela". Abre-se então a possibilidade quase necessária de que o roteiro se utilize poeticamente do diálogo estabelecido entre o conteúdo projetado e a arquitetura interlocutora. No caso do projeto ETM o desenvolvimento desse diálogo se deu alimentado pelos conceitos de 'beleza', 'tautologia da imagem' e 'presença', tal como são trabalhados, respectivamente, por Roger Scruton, Geoges Didi-Huberman e Hans Ulrich Gumbrecht, na medida em que, com a ajuda desses conceitos, pôde-se jogar com as balizas objetivas impostas pela monumentalidade do suporte e a transitoriedade da audiência, para a construção de um roteiro onde o prédio fosse "parceiro" na dança com os bailarinos. Ainda que este parceiro apresentasse uma dança sutil - uma vez que optou-se pela utilização dos efeitos visuais que não explicitassem simulações de movimentações por parte da construção - ele é claramente presente e partícipe na obra, seja auxiliando na simulação de certo anonimato dos bailarinos dançando em suas janelas, seja recebendo a pintura nos rastros dos movimentos dançados. Dessa forma, o roteiro trata o edifício como personagem ativo.

As cenas precisaram prever um público que apreciaria o video mapping de mais de uma maneira, sendo capturado em mais de uma situação possível, as quais o roteiro precisava necessariamente considerar. Cada cena serviu como oportunidade de convidar o espectador a seguir assistindo ao filme, ao mesmo tempo que deveria tocar, de maneira singular, a temática tratada: o afeto na contemporaneidade. Através da análise do roteiro, este artigo apresentou a maneira como esse objetivo foi alcançado em cada cena, ao mesmo tempo que acontecia a necessária negociação com aquilo que entendemos por balizas objetivas da elaboração desse video 
mapping. Os mesmos aspectos poderão ser encontrados em outros video mappings. O próprio projeto ETM, a cada nova realização em outras superfícies, exige mudanças no roteiro a fim de contemplar outros diálogos. Abre-se, então, a oportunidade, com as realizações que o projeto vem desenvolvendo desde então, para a análise das adaptações que o roteiro precisa sofrer a cada mudança de superfície. O diálogo entre projeção e construção precisa, em cada caso, de ser refeito e o estudo dessa relação poderá ser o próximo passo da pesquisa.

\section{BIBLIOGRAFIA}

Bruno, Giuliana. 2015. "Ruínas Modernistas, Arqueologias Fílmicas: A Free and Anonymous Monument, de Jane e Louise Wilson". Aniki vol. 2, n. ${ }^{\circ}$ 1. Disponível em: <http://aim.org.pt/ojs/index.php/revista/article/view/145/ pdf $>$. Acesso em 09 de setembro de 2019.

Colomina, Beatriz. 2009. "Enclosed by images: the eameses' multiscreen architecture". In: Douglas, Stan; Eamon, Christopher. Art of Projection. Ostfildern (Alemanha): Hatje Cantz Verlag, 36-56.

Diário Oficial do Município do Rio de Janeiro, 2015. Ano XXIX. Nº 166. Rio de Janeiro, 69.

Didi-Huberman, Georges. 2005. O que vemos, o que nos olha. São Paulo: Ed. 34.

Faulkner, Michael; D-FUSE. 2006. Audio-visual Art + VJ Culture. UK: Laurence King Publishing.

Garcia, Rafael de Oliveira. 2014. Video Mapping: Um estudo teórico e prático sobre projeção mapeada. São Paulo: Universidade Estadual Paulista (Trabalho de Conclusão do Curso de Comunicação Social).

Gumbrecht, Hans Ulrich. 2010. Produção de presença: o que o sentido não consegue transmitir. Rio de Janeiro: Contraponto: Ed. PUCRio.

Kemp, Philip. 2011. Tudo sobre cinema. Rio de Janeiro: Sextante.

Lehmann, Hans-Thies. 2007. Teatro pós-dramático. São Paulo: Cosac \& Naify.

Leighton, Tanya. 2008. Art and the Moving Image: a Critical Reader. London: Tate, Afterall.

McDounough, Thomas. 2009. "Production/Projection: notes on the capitalist fairy tale”. In: Douglas, Stan; Eamon, Christopher. Art of Projection. Ostfildern (Alemanha): Hatje Cantz Verlag, 124140.

Mota, Márcio Hofmann. 2014. Video mapping / projeção mapeada: espaços imaginários delocáveis. Brasília: Programa de PósGraduação em Artes (Dissertação Universidade de Brasília). 
Pavis, Patrice. 2008. Dicionário de Teatro / Patrice Pavis. Tradução para a língua portuguesa sob a direção de J. Guinsburg e Maria Lúcia Pereira. 3. Ed. São Paulo: Perspectiva.

Romano, Lúcia. 2008. O teatro do corpo manifesto: Teatro Físico. São Paulo: Perspectiva.

Rush, Michael. 2007. Video Art. London: Thames \& Hudson.

Scruton, Roger. 2013. Beleza. São Paulo: É Realizações Editora.

\section{MAPPINGS}

Anadol, Refik; et al. Spatium [Vidcast online]. Istambul: Istanbul Technical University, 2011. 6 mins e 15 secs. Video mapping realizado no Taşkışla Festival 17 em 13 de maio de 2011. Disponível em: https://vimeo.com/23759892 . Acesso em 26 de fevereiro de 2018.

InSynchLab. Architectural mapping Montenegro Cetinje [Vidcast online]. Cetinhe (Montenegro): Andromeda Pictures, 2012. 10 mins e $01 \mathrm{sec}$. Video Mapping realizado na ocasião da festa nacional de Montenegro, na cidade de Cetinhe, sobre o Palácio do Rei Nicola em 18 de maio de 2012. Disponível em: https://vimeo.com/53067262. Acesso em 26 de fevereiro de 2018.

Nuformer. First $3 D$ video mapping projection [Vidcast online]. Zierikzee (Holanda): Nuformer, 2009. 2 mins e 26 secs. Video mapping realizado na fachada da New Church em 16 de julho de 2009. Disponível em: http://www.nuformer.com/portfolio/item/first_projection/. Acesso em 26 de fevereiro de 2018.

Void; et al. Lines [Vidcast online]. Romania: Maxin10sity, 2016. 5 mins. Video mapping realizado no Palace do Parlamento em Bucareste. Disponível em: https://vimeo.com/195627218. Acesso em 26 de fevereiro de 2018.

Cia Gelmini de Videodança. ETM Teaser. Rio de Janeiro: Tetra Filmes, 2016. 4 mins e 18 secs. Canal da produtora na plataforma VIMEO. Disponível em: https://vimeo.com/169936885. Acesso em 12 de março de 2018. 